\title{
CYBERLOAFING SEBAGAI STRATEGI MENGATASI KEBOSANAN KERJA
}

\author{
Siti Nur Azizah \\ Progam Studi Manajemen \\ STIE Putra Bangsa Kebumen \\ sitinuraziz@yahoo.com
}

\begin{abstract}
Cyberloafing has been considered as a form of opposite / unproductive work behavior (CWB) that can endanger organizations. This study takes a different view that cyberloafing can show a potentially positive function in this context that can help employees overcome boredom at work. The sample of this study was 70 administrative employees at junior high schools in Kebumen which were taken randomly. By using PLS assistance we tested the relationship between low work underload on cyberloafing and counter-productive behavior with boredom as mediators. The results of the study indicate boredom mediates the work underload and cyberloafing relationship. Cyberloafing is used by employees as a coping strategy (adaptive behavior) to overcome work boredom compared to counter-productive behavior
\end{abstract}

Keywords: Cyberloafing, work underload, kebosanan, counter productive work behavior $(C W B)$

\section{PENDAHULUAN}

\section{Latar Belakang}

Kebosanan dan cyberloafing di tempat kerja adalah dua topik yang semakin umum yang menarik dalam organisasi dalam penelitian dalam beberapa tahun terakhir. Di sisi organisasi, ada kebutuhan untuk memahami cyberloafing karena ada pendapat umum bahwa cyberloafing adalah perilaku kontraproduktif, menyimpang dari norma-norma organisasi, dan dapat menyebabkan biaya untuk organisasi (Askew, 2012; Askew et al., 2014; Everton, Mastrangelo, \& Jolton, 2005). Demikian pula, karyawan yang bosan dianggap merusak organisasi (Brursema, Kessler, \& Spector, 2011; Harju, Hakanen, \& Schaufeli, 2014).

Para karyawan merasakan kebosanan di tempat kerja sebagai aspek penting dari pengalaman kerja, mengurangi kesejahteraan karyawan (van Hooff \& van Hooft, 2014, 2016) dan cyberloafing bisa sebagai respon penanggulangan terhadap kebosanan. Dalam studi saat ini, kami mengambil perspektif karyawan dan memeriksa bagaimana kebosanan di tempat kerja, yang dihasilkan dari tingkat beban kerja yang rendah, dapat mengarah pada cyberloafing sebagai cara mengatasi (perilaku adaptif).
Pegawai Tata Usaha di sekolah memiliki tugas administratif antara lain mengagendakan surat masuk/keluar, mengetik surat, menggandakan surat-surat, mengarsipkan, menata penomoran surat, merapikan file-file surat, mengirim dan menerima surat-surat, menyusun dan menyajikan data statistik sekolah. Selain itu mereka juga memiliki kewajiban mengurus dokumen-dokumen sekolah dan menyusun laporan-laporan ketatausahaan sekolah yang berhubungan dengan siswa, sarana prasaran, kurikulum dan kepegawaian. Tugas tugas tersebut menuntut ketrampilan komputer (computer literacy) dan rutinitas yang tinggi pada deadline penyusunan laporan namun rentan menyebabkan kebosanan saat masa antara dimana tidak banyak tugas.

Berdasarkan pengamatan, karyawan tata usaha sekolah yang bisa mengakses komputer secara online cenderung melakukan aktivitas online seperti berselancar, membuka media sosial dan berbelanja online. cyberloafing dapat menjadi mekanisme penanggulangan bagi karyawan yang mengalami kebosanan di tempat kerja. 


\section{KAJIAN PUSTAKA}

\section{Cyberloafing di tempat kerja}

Cyberloafing didefinisikan sebagai penggunaan pribadi atau rekreasi perangkat elektronik padahal karyawan seharusnya melakukan tugas pekerjaan (Lim \& Teo, 2005; Lim, 2002). Dalam beberapa dekade terakhir, penggunaan internet dalam organisasi telah menjadi kebutuhan. Namun, akses ke internet di tempat kerja menyediakan alternatif mudah yang dapat bersaing dengan tugas kerja karyawan.

Cyberloafing dapat dianggap sebagai jenis perilaku kerja kontraproduktif/CWB, perilaku yang merugikan organisasi dan pemangku kepentingan organisasi (Spector et al., 2006). CWB mengikutsertakan beberapa dimensi: penyalahgunaan, penyimpangan produksi (misalnya, sengaja bekerja lambat atau salah), sabotase (misalnya merusak peralatan), pencurian (misalnya, lebih banyak internet-an daripada benar-benar bekerja) dan datang terlambat. Cyberloafing secara konseptual paling dekat dengan penyimpangan produksi, yaitu melakukan pekerjaan dengan tidak benar (Lim, 2002), dan bekerja kurang dari waktu yang dibutuhkan (Askew, 2012); Bentuk yang umum untuk studi cyberloafing adalah asumsi bahwa cyberloafing adalah perilaku negatif atau kontraproduktif.

Dalam penelitian ini kami mengambil pendekatan yang berbeda, yaitu cyberloafing dapat menjadi mekanisme penanggulangan bagi karyawan yang mengalami kebosanan di tempat kerja. Perspektif koping ini sejalan dengan temuan sebelumnya bahwa cyberloafing secara positif terkait dengan kesejahteraan emosi karyawan (Lim \& Chen, 2012). Secara khusus, penelitian ini memeriksa hubungan antara beban kerja, kebosanan, dan cyberloafing. Beberapa penelitian telah meneliti hubungan semacam itu; seperti (Andreassen et al., 2014; Henle \& Blanchard, 2008) telah menemukan bahwa tuntutan kerja kuantitatif berhubungan negatif dengan cyberloafing, dan bahwa tuntutan kerja yang rendah terkait dengan kebosanan tempat kerja yang lebih besar (Metin, Taris, \& Peeters, 2016).

\section{Beban Kerja}

Beban kerja, jumlah pekerjaan yang dirasakan dalam hal kesulitan, volume dan kecepatan (Bowling \& Kirkendall, 2012; Spector \& Jex, 1998), biasanya dipelajari dari perspektif stres dalam hal beban kerja yang terlalu besar (over load) dan berhubungan negatif pada hasil kerja karyawan dan organisasi (Bowling, Alarcon, Bragg, \& Hartman, 2015). Bekerja di bawah beban (underload) adalah memiliki beban kerja yang relatif rendah, dipelajari sebagai potensial stressor. Sedangkan beban kerja berlebih (Bowling et al., 2015) berkorelasi positif dengan peran konflik, konflik kerjakeluarga, dan kelelahan emosional.

Akibat beban kerja rendah, karyawan kemudian dapat terlibat dalam perilaku seperti cyberloafing atau perilaku kerja kontra-produktif. Satu studi secara khusus berfokus pada beban kerja yang lebih rendah (Shultz, Wang, \& Olson, 2010) dan menemukan bahwa underload memiliki efek negatif pada sebagian besar gejala fisik, kelelahan, masalah tidur, dan kecemasan. Kebosanan di tempat kerja ditemukan memprediksi perasaan depresi pada akhir hari kerja (van Hooff \& van Hooft, 2016).

Hasil-hasil yang berkaitan dengan beban kerja dibawah tekanan ternyata kebanyakan telah diabaikan. Sedikit penelitian yang menguji tentang dibawah tekanan kerja yang akhirnya sering menjadi bengkok atau hubungan bentuk-U dengan hasil-hasilnya. Sebagai misal, banyak kondisi untuk permintaaan-permintaan pekerjaan (contohnya beban kerja) memiliki sebuah hubungan terbalik dari bentuk-U dengan prestasi dan kepuasan (Jansen, 2001). Sementara tanpa mengukur beban kerja secara langsung, (Xie dan Johns,1995) menemukan bahwa ruang lingkup pekerjaan memiliki hubungan bentuk-U dengan keletihan emosional dan akhirnya tekenan kerja memiliki hubungan terbalik bentuk-U dengan komitmen perusahaan dan prestasi 
kerja (Chen, Silverthorne dan hung 2006, Leung, Chan dan Olomulaiye, 2008). Penemuan-penemuan tersebut mendukung ide/gagasan bahwa ada sebuah tingkatan aktivasi optimal (Gardner,1986), dan ketika tingkatan-tingkatan aktivasi terlalu rendah, maka pekerjaaan para pegawai dan prestasi kerja mengalami kegagalan. Beban kerja dapat menjadi penggerak tingkatan aktivasi untuk para pegawai. Dalam tingkatan beban kerja yang rendah, ketika ada hal yang sedikit untuk dilakukan, maka aktifasi juga rendah. Jika beban kerja naik, begitu juga akatifasi, akan ikut meningkat pada level tinggi shg tingkatan aktivasi optimal dapat dilampaui. Para pegawai kemudian mungkin menjalankan dalam perilaku kerja seperti kemalasan atau perilaku-perilaku kerja berlawanan/tidak produktif.

\section{Kebosanan di tempat kerja}

Kebosanan di tempat kerja adalah aspek penting dari pengalaman kerja yang belum mendapat cukup perhatian sampai saat ini (Mael \& Jex, 2015). Namun demikian, pengalaman kerja yang lazim di banyak industri, dan dikaitkan dengan tingkat perputaran karyawan yang lebih besar, kesehatan yang dilaporkan sendiri yang lebih buruk dan peningkatan stres, dan mengurangi kinerja tugas (Cummings, Gao, \& Thornburg, 2016; Harju et al., 2014). Kebosanan adalah "keadaan tidak menyenangkan dari gairah dan ketidakpuasan yang relatif rendah, yang dikaitkan dengan situasi kerja yang tidak cukup merangsang" (Schaufeli \& Salanova, 2014, hlm. 298). Hal ini sering merupakan hasil dari karakteristik tempat kerja (Loukidou, Loan-Clarke, \& Daniels, 2009), tetapi elemen-elemen kerja ini berkorelasi dengan kebosanan di tempat kerja. Kebosanan di tempat kerja memiliki kecenderungan untuk membuat karyawan merasa kehilangan makna di tempat kerja (Van Hooft, 2016), dan paling sering didefinisikan sebagai ketegangan emosional (yaitu, penurunan kesejahteraan akibat stres).

\section{Cyberloafing sebagai strategi mengatasi kebosanan}

Cyberloafing adalah pengalihan perhatian karyawan dari tugas kerja mereka ke masalah pribadi atau rekreasi. Dalam hal itu, cyberloafing dapat membentuk aktivitas mengatasi kebosanan karena mengubah situasi membosankan di tempat kerja untuk memasukkan komponen yang lebih menarik (meskipun bersifat pribadi). Dalam studi pendahuluan, Game (2007) menemukan bahwa karyawan menggunakan berbagai cara untuk mengatasi kebosanan dalam pekerjaan, dan mereka mencoba untuk membuat pekerjaan lebih menarik) atau melepaskan coping (yaitu, perilaku yang menghindari tugas). Serupa dengan melepaskan diri mengatasi, kebosanan di tempat kerja terkait dengan gangguan sebagai bentuk strategi bantuan sementara (Van der Heijden, Schepers, \& Nijssen, 2012). Penggunaan teknologi komunikasi pribadi di tempat kerja (yaitu, cyberloafing) adalah hasil dari insentif self-reactive untuk menghilangkan kebosanan (Eastin, Glynn, \& Griffiths (2007), dan aktivitas cyberloafing tertentu memiliki efek positif pada emosi karyawan. (Lim \& Chen, 2012).

\section{METODE PENELITIAN}

\section{Variabel Penelitian}

Cyberloafing. Penelitian ini menggunakan indikator dari Lim dan Teo (2005) skala kemalasan yang mengukur frekuensi dalam penggunaaan internet untuk kepentingan individual di tempat kerja. Hal tersebut diukur menggunakan skala poin 5 yang diurutkan dari 'tidak pernah' ke 'terus menerus'.

Kebosanan. skala kebosanan yang digunakan adalah indikator menurut Lee (1986).

Work underload. Penelitian ini menggunakan indikator Spector dan Jex (1998), beban kerja quantitative pada skala 5 digunakan untuk mengukur beban kerja. Hal tersebut dijumlah pada skala poin 5 yang diranking dari 'kurang dari sekali per bulan 
atau tidak pernah' ke 'beberapa kali perhari'. Sebuah skor yang rendah pada skala ini member petunjuk adanya work underload

Counter work behavior (CWB). Penelitian ini menggunakan(Spector, Bauer, dan Fox, 2010). Sampelnya adalah 'Seberapa sering Anda secara sengaja membuangbuang materi atau fasilitas perusahaan. Responnya diberikan pada skala poin 5 yang

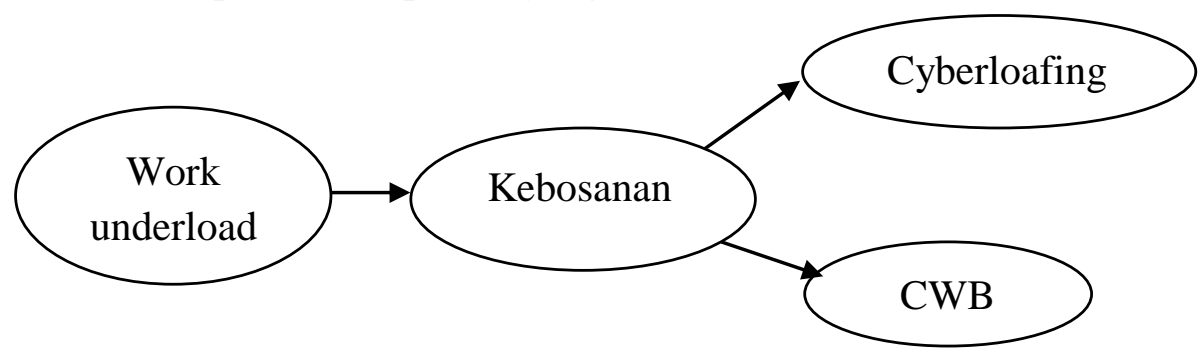

\section{Gambar 1. Kerangka pikir}

\section{Hipotesa Penelitian}

Hasil penelitian Pindek et all (2018) menyatakan adanya mekanisme strategi koping para karyawan yang mengalami kebosanan karena adanya work underload kerja dengan cyberloafing. Sehingga hipotesa yang dibangun pada penelitian ini adalah:

H1:Work underload berpengaruh terhadap cyberloafing

$\mathrm{H} 2$ :Kebosanan berpengaruh terhadap cyberloafing

H3:Kebosanan memediasi pengaruh work underload dengan cyberloafing

H4:Hubungan kemalasan-kebosanan lebih kuat dari hubungan CWB-kebosanan.

\section{Populasi dan Sampel}

Populasi penelitian adalah pegawai tata usaha sekolah menengah pertama di Kebumen sejumlah 207. Peneliti menggunakan email untuk pengisian kuesioner dan data yang kembali dan dapat diolah sebanyak 70. Peneliti menggunakan software SPSS untuk menentukan hasil validitas, realibilitats serta normalitas. Selanjutnya, kami menguji model hipotesa diranking dari 'tidak pernah' ke 'setiap hari'. Konsistensi internal tidak dihitung karena sekalanya bersifat formatif.

\section{Kerangka Pikir}

Berdasarkan kajian pustaka dan latar belakang penelitian, maka kerangka pikir dalam penelitian ini adalah sebagai berikut: dan hubungan antar variabel dengan menggunakanPLS.

\section{HASIL PENELITIAN}

\section{Statiktik deskriptif}

Pada penelitian ini sebanyak 60 persen responden adalah perempuan yaitu 42 orang dan 28 responden (40 persen) adalah lakilaki. Responden dengan usia 20-25 tahun sebanyak 26 orang (37\%), sedangkan jumlah responden pada usia 26-30 tahun sebanyak 20 orang (29 \%). Sebanyak 19 responden (27\%) berusia 31-35 tahun sedangkan sisanya 5 orang $(7 \%)$ berusia lebih dari 36 tahun.

Hasil total jawaban untuk workload dari tiga butir pernyataan menunjukkan jumlah jawaban adalah 138 skor dari total 350 skor untuk butir satu (di tempat kerja tidak banyak pekerjaan yang dilakukan), 131 skor dari 350 skor untuk jawaban butir 2 (di tempat kerja saya menghabiskan waktu dengan percuma), 128 skor dari 350 skor untuk jawaban butir 3 (selama kerja saya banyak melamun). Hal ini menunjukkan skor yang rendah sehingga menunjukkan adanya work under load. 
Uji Validitas, Reliabilitas Dan Normalitas

Peneitian ini menggunakan bantuan SPSS untuk menguji validitas, reliabilitas dan normalitas data yang menunjukkan hasil sebagai berikut:

Tabel 1. Uji Validitas

\begin{tabular}{llllllll}
\hline $\begin{array}{l}\text { Work } \\
\text { underload }\end{array}$ & $\begin{array}{l}\text { R } \\
\text { hitung }\end{array}$ & Kebosanan & $\begin{array}{l}\mathbf{R} \\
\text { hitung }\end{array}$ & Cyberloafing & $\begin{array}{l}\mathbf{R} \\
\text { hitung }\end{array}$ & CWB & $\begin{array}{l}\text { R } \\
\text { hitung }\end{array}$ \\
\hline WU 1 & 0,863 & K1 & 0,886 & C1 & 0,586 & CWB1 & 0,524 \\
WU 2 & 0,908 & K2 & 0.897 & C2 & 0,497 & CWB2 & 0,634 \\
WU3 & 0,863 & & & C3 & 0,478 & CWB3 & 0,737 \\
& & & & C4 & 0,795 & CWB4 & 0,509
\end{tabular}

Sumber: Data primer diolah 2019

Berdasarkan tabel 1 maka semua butir pernyataan adalah valid karena $r$ hitung lebih besar dari $r$ tabel $(0,279)$. Pengolahan statistik untuk uji realibilitas menunjukkan alpha cronbach diatas 0,6 , yaitu untuk

Cyberloafing sebesar 0,85, variabel work underload sebesar 0,88 dan variabel kebosanan sebesar 0,89 . Sedangkan variabel CWB tidak dihitung relaibilitasnya karena skalanya bersifat formatif.

\section{Tabel 2. Uji Reliabilitas}

\begin{tabular}{ll}
\hline Variabel & $\begin{array}{l}\text { Alpha } \\
\text { cronbach }\end{array}$ \\
\hline Work underload & 0,88 \\
Cyberloafing & 0,85 \\
Kebosanan & 0,89 \\
\hline
\end{tabular}

Sumber: Data primer diolah 2019

Pengujian normalitas menggunakan Kolmogorof Smirnov menunjukkan hasil sig diatas 0,05 yaitu 0,069 sehingga data tersebar dengan normal.

\section{Uji t}

Uji pengaruh menunjukkan hasil sebagai berikut: Hipotesa 1 ditolak dengan $p$ value 0,147 menunjukkan work underload tidak berpengaruh signifikan terhadap cyberloafing. Hipotesa 2 diterima dengan $\mathrm{p}$ value 0,00 kebosanan berpengaruh terhadap cyberloafing.

\section{Uji Jalur}

Hipotesa 3 didukung sebagai cara tidak langsung antara work underload dan cyberloafing melalui kebosanan. Artinya kebosanan memediasi secara penuh (full mediasi) hubungan work underload dan cyberlaofing. 


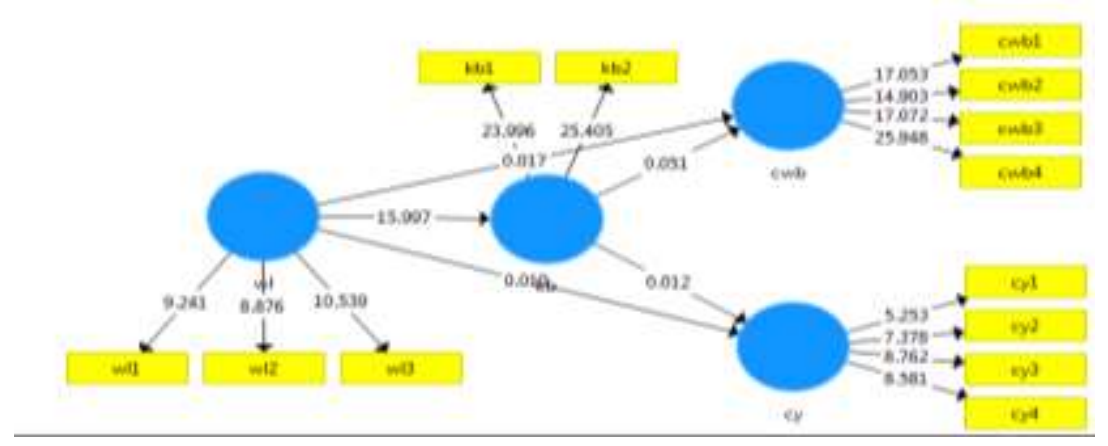

Gambar 2. Uji Jalur

Penelitian ini juga menemukan hasil koefisien korelasi kebosanan dengan cyberloafing yang lebih besar $(\mathrm{y}=0,46)$ dengan koefisien korelasi kebosanan dibandingkan dengan CWB $(\mathrm{y}=0,27)$ sehingga Hipotesa 4 diterima.

\section{PEMBAHASAN}

Penelitian sekarang ini menguji bagaimana kebosanan ditempat kerja, akibat tekanan kerja, dapat mengakibatkan cyberloafing sebagai solusi yang sesuai. Hipotesis penelitian terbukti diterima dengan penambahan kerangka literature yang bekembang untuk menanggulangi efek-efek negative dalam tekanan kerja bagi para pegawai (Shuclt dkk, 2010) serta untuk menjelajahi konsep cyberloafing sebagi mekanisme penanganan rasa bosan (Lim dan Chen, 2012; Van der Heijden dkk, 2012) dari pada sebagai CWB. Hal ini dibuktikan hubungan antara kebosanan dan cyberloafing lebih kuat dari pada hubungan kebosanan dengan CWB. Hal ini memberikan poin untuk cyberloafing menjadi suatu strategi penanggulangan kebosanan bagi kebanyakan pegawai.

Penelitian ini memiliki implikasi praktis, misalnya cyberloafing dapat digunakan sebagai indikasi rasa bosan dalam bekerja dan organisasi melakukan upaya agar para pegawai lebih produktif misalnya membatasi jam dan akses internet untuk hal yang bersifat hiburan serta mengganti dengan media sosial yang bersifat interaktif.

Keterbatasan penelitian ini antara lain terbatasnya variabel yang diteliti. Variable lain seperti kepuasan kerja berpotensi menghubungkan CWB dan cyberloafing. Selain itu sampel penelitian ini terbatas dengan pekerjaan yang sama yaitu staf tata usaha, sehingga disarankan dilakukan penelitiannya untuk para pegawai dalam pekerjaan yang berbeda.

\section{REFERENSI}

Bruursema, K., Kessler, S. R., \& Spector, P. E. (2011). Bored employees misbehaving: The relationship between boredom and counterproductive work behaviour. Work \& Stress, 25(2), 93e107. https://doi.org/10.1080/02678373.2011 .596670 .

Van der Heijden, G. A. H., Schepers, J. J. L., \& Nijssen, E. J. (2012). Understanding workplace boredom among white collar employees: Temporary reactions and individual differences. European Journal of Work \& Organizational Psychology, 21(3), $349 \mathrm{e} 375$. https://doi.org/10.1080/1359432X.201 1.578824 .

Van Hooff, M. L. M., \& van Hooft, E. A. J. (2014). Boredom at work: Proximal and distal consequences of affective work-related boredom. Journal of Occupational Health Psychology, 19(3), 348e359. https://doi.org/10.1037/a0036821.

Van Hooff, M. L. M., \& van Hooft, E. A. J. (2016). Work-related boredom and depressed mood from a daily 
perspective: The moderating roles of work centrality and need satisfaction. Work \& Stress, 30(3), $209 \mathrm{e} 227$. https://doi.org/ 10.1080/02678373.2016.1206151.

Lim, V. K. G. (2002). The it way of loafing on the job: Cyberloafing, neutralizing and organizational justice. Journal of Organizational Behavior, 23(5), $675 \mathrm{e} 694$. https://doi.org/10.1002/job.161.

Lim, V. K. G., \& Chen, D. J. Q. (2012). Cyberloafing at the workplace: Gain or drain on work? Behaviour \& Information Technology, M31(4), 343e353. https://doi.org/ 10.1080/01449290903353054.

Lim, V. K. G., \& Teo, T. S. H. (2005). Prevalence, perceived seriousness, justification and regulation of cyberloafing in Singapore. Information \& Management, 42(8), 1081e1093. https://doi.org/10.1016/j.im.2004.12.00 2.

Spector, P. E., Bauer, J. A., \& Fox, S. (2010). Measurement artifacts in the assessment of counterproductive work behavior and organizational citizenship behavior: Do we know what we think we know? Journal of Applied Psychology, 95(4), 781e790. https://doi.org/10.1037/a0019477.

Spector, P. E., \& Fox, S. (2010). Counterproductive work behavior and organisational citizenship behavior: Are they opposite forms of active behavior? Applied Psychology, 59(1), 21e39. https://doi.org/10.1111/j.14640597.2009.00414.x.

Spector, P. E., Fox, S., Penney, L. M., Bruursema, K., Goh, A., \& Kessler, S. (2006). The dimensionality of counterproductivity: Are all counterproductive behaviors created equal? Journal of Vocational Behavior, 68(3), 446e460. https://doi.org/ 10.1016/j.jvb.2005.10.005.

Spector, P. E., \& Jex, S. M. (1998). Development of four self-report measures of job stressors and strain: Interpersonal conflict at work scale, organizational costraints scale, quantitative workload inventory, and physical symptoms inventory. Journal of Occupational Health Psychology, 3(4), 356e367. https:// doi.org/10.1037/1076-8998.3.4.35 